\title{
МОДЕРНИЗАЦИЯ РОССИЙСКОЙ ЭКОНОМИКИ В УСЛОВИЯХ ТРАНСФОРМАЦИИ СОЦИАЛЬНОЙ СТРУКТУРЫ ОБЩЕСТВА
}

\author{
(c) 2018 Наумов Александр Сергеевич \\ кандидат экономических наук, старший научный сотрудник \\ Институт экономики РАН \\ 117218, г. Москва, Нахимовский пр., д. 32 \\ E-mail: as.naumov@mail.ru
}

Выделяются причины объективной необходимости модернизации российской экономики в условиях трансформации социальной структуры общества, раскрывается влияние этой структуры на выбор стратегических приоритетов данной модернизации, анализируются особенности формирования общественной системы, рассматривается зарубежный опыт формирования среднего класса как средства снятия социальных противоречий в процессе модернизации, излагается авторская точка зрения по рассматриваемым вопросам.

Ключевые слова: модернизация российской экономики, социальная структура, стратификация, социальные противоречия, способ производства, технологический уклад, социально-экономическое развитие, экономический уклад, средний класс, инвестиции, инновации.

Общеизвестно, что одной из ключевых проблем российской экономики является проблема ее модернизации. Объективная необходимость последней обусловлена внутренними и внешними причинами.

K внутренним причинам относится износ основных производственных фондов, отрицательно влияющих на создание современной ресурсной базы; негативная роль сырьевой зависимости экономики в изменении структуры институциональных трансформаций, направленных на создание современных переходов к постэкономическому развитию российской экономики; слабая инвестиционная и инновационная активность; отсутствие конкуренции; неразвитость инфраструктуры; острая нехватка высококвалифицированных кадров в базовых отраслях российской экономики, обуславливающая низкую производительность труда в сравнении с развитыми экономиками; существенное снижение объема инвестиций в основной капитал, являющееся барьером подъема экономики и ее устойчивого роста; наличие чиновничьего монополизма и возрастающей коррупции (в условиях отсутствия зрелого гражданского общества), исключающее саму возможность быстрого развития российского предпринимательства, эффективного взаимодействия государства и бизнеса; резкое углубление социально-экономического неравенства различных слоев населения, что создает угрозу стабильности российского общества; проблемы управления экономикой; от- сутствие четко ориентированных связей между наукой и бизнесом, образованием и производством.

K наиболее важным внешним причинам следует отнести: технико-технологическое отставание России от ведущих стран мира, преодоление которого послужит отправным пунктом устойчивого роста и модернизации отечественной экономики; низкая конкурентоспособность России на мировых товарных рынках; крайне низкий удельный вес России в мировой экономике; офшоризация российского капитала; резкое обострение конкурентной борьбы за энергоресурсы на мировых рынках; введение ЕС и США экономических санкций против нашей страны в 2014 году, усугубляющих и без того не простое положение отечественной экономики.

В этой связи важно отметить одно весьма важное обстоятельство. Оно касается оптимального выбора вида модернизации. Как полагают исследователи, здесь «следует исходить из того, что в современных условиях модернизация может включать в себя и постиндустриализацию, и альтер- модернизацию, а также может являться в деформированном виде. Ее сведение к чистому, стандартизированному индустриализму в настоящее время неперспективно» [1 с. 61].

Ключевую роль при выборе этого вида приобретает решение проблемы структурных противоречий, оказывающих непосредственное влияние на модернизацию российской экономики. Суть этой проблемы заключается в опре- 
делении оптимального баланса интересов различных социальных групп. Подчеркнем, она отягощена тем обстоятельством, что технологические изменения в экономике, как правило, всегда опережают появление соответствующих им социальных слоев. В этом случае на первый план выдвигается государство, которое должно оказывать решающее воздействие на устранение этих противоречий при выборе стратегического курса модернизации самой экономики, соответствующего современным формам общественного развития. Нужно, однако, отметить, что главная трудность при этом заключается в том, чтобы учесть те коренные изменения, которые обусловлены переходом от индустриальной к постиндустриальной экономике, или экономики знаний.

Вследствие этих изменений особую актуальность приобретает проблема трансформации социально-экономических и политических процессов, обусловленных трудностям институционального порядка. Так, сложившаяся в нашей стране в течение ряда десятилетий, огосударствленная общественная система, возникновение которой не вытекало из естественного хода истории, а являлось детищем государства, влияла и продолжает влиять на изменение социальной структуры общества с точки зрения верховенства государственной власти. По мнению Л.В.Никифорова, «в России изменение политической составляющей общественной системы произошло раньше, чем были созданы предпосылки смены характера других сторон общественных отношений. Поэтому дальнейшие направления общественных перемен оказались в зависимости от развития и трансформации социально-политических отношений и институтов» [2, с. 16].

К сожалению, становление новой общественной системы и соответствующей ей социальной структуры в постсоветский период осуществлялось в значительной мере под влиянием указанных процессов. Однако определение этой социальной структуры наталкивается на слишком размытые критерии, касающиеся их трактовки, как по формам собственности, так и по профессиональной деятельности. Причина заключается в неустойчивости вновь образовавшихся слоев и страт. В связи с этим процесс трансформации последних должен осуществляться в контексте тех задач, которые позволяли бы перейти к следующему этапу технологического развития.
Главная трудность при этом состоит в том, что экономические преобразования невозможны без политической и социальной трансформации общества, а значит и изменения его структуры. Исторический опыт показал, что в качестве необходимой предпосылки модернизации экономики всегда выступает трансформация социальной структуры общества.

В связи с этим достаточно интересен опыт трансформации китайского общества. «Изменения и новые вызовы, стоящие перед ним (Китаем), реконструкция общественного порядка и есть инновации в социальном управлении»,утверждает китайский исследователь Ли Лу [3, c. 29]. Он предлагает раскрыть социальную основу, природу отношений и векторы, ориентированные на реализацию интересов. Инновации же необходимы, по мнению Ли ЛУ, в связи с проблемами, вызванными радикальными изменениями.

Заметим, в современной России имеют место аналогичные проблемы: необходимо привести в соответствие модернизацию экономики и социальную структуру общества и избежать при этом возникающие противоречия.

Именно поэтому можно использовать опыт современного Китая, в разрешении противоречий и преодоление конфликтов между различными слоями и группами посредством перераспределения ресурсов и создания адекватной социальной среды. При этом их доступ к ресурсам (финансовым, природным, политическим) имеет решающее значение.

Чрезвычайно важную роль в формировании этой среды имеет средний класс, наличие которого имманентно любой развитой стране Запада, что является гарантом движения вперед. Это класс включает в себя различные слои населения: бизнесменов, ученых, педагогов, врачей, деятелей культуры и квалифицированных работников, которые присущи любому современному обществу, но их влияние на социально-экономические и политические процессы совершаются по-разному. Суть дела здесь заключается не только в наличии соответствующих капиталов и зарплат, но и в инновационных вызовах, обусловленных изменениями социально-институциональной среды.

В России дело обстоит несколько иначе: национальное богатство находится в руках олигархов. В то же время формирование среднего класса сдерживается рядом негативных факто- 
ров: трудностью доступа к ресурсам страны, резкому расслоению населения по доходам и качеству жизни (нищие, бедные, малообеспеченные, среднеобеспеченные, обеспеченные, состоятельные) и др.

В этой связи ученые обращают внимание на тот факт, что процессы стратификации, происходящие в современном российском обществе, обнаруживают в себе «социально- и культурно-деформированный характер» [4, с. 3]. В будущем возможно появятся изменения в стратах, которые позволят интегрироваться в современную мировую общность на основе своих ментальных предпочтений.

Одним из таких основных изменений является система подготовки специалистов в российских высших учебных заведениях, выпускники которых зачастую не имеют четкого представления о перспективах своей дальнейшей деятельности.

Кроме того, вызывает опасение и возросшая эмиграция высококвалифицированных специалистов. Так, «в 2013 году из Российской Федерации выбыло 186 тысяч граждан, такого полноводного потока не наблюдалось с 1999 года, когда нашу страну покинуло 215 тысяч человек. В 2014 году уехало еще больше, за первые восемь месяцев эмигрировало 203 тысячи человек, об этом сообщал Росстат» [5, с. 1].

Необходимо подчеркнуть то, что Россию покидают в основном молодые, образованные, энергичные люди, которые закрепляются в США, Германии, Канаде, Великобритании, Финляндии, внося свой вклад в фундаментальную науку этих стран.

По мнению С. Варыханова «на протяжении двух десятков лет в нашей стране утвердилось «отрицательное замещение трудовых ресурсов» - уезжают образованные высококвалифицированные специалисты, приезжают граждане бывших советских республик с низкой профессиональной квалификацией или вовсе без профессии, работники-универсалы, которые могут копать и могут не копать» [6, с. 1]. Такие оценки все чаще появляются в средствах массовой информации. Ответ прост - люди уезжают, чтобы повысить качество жизни там, где государство может адекватно ответить на вызовы современного мира, т.е. за будущим.

Для понимания сути происходящих процессов следует обратиться к истории подобных трансформационных процессов в развитых странах Запада. Например: Президент США Ф. Рузвельт видел причины Великой депрессии в господстве в США радикального либерализма, который, по его словам, сковал «экономику» посредством «погони за незаработанным богатством». Проявления радикального либерализма везде одинаковы. В современной России те же проблемы. Что же декларирует президент США в весьма понятийной форме? «... Но мы считаем, что, если гражданин имеет равные права на избирательном участке, он должен иметь равные права и на рынке труда. Эти экономические роялисты жалуются, что мы стремимся сокрушить базовые американские установления. На самом деле они боятся, что мы лишим их власти. Наша приверженность американским установлениям требует от нас изменить этот порядок вещей. Зря, они прячутся за нашим национальным флагом и за конституцией». Аудитория теперь слушала стоя. «Демократия, а не тирания, свобода, а не подчинение... Враг стоит внутри наших стен» [7, с. 158-159]. Причины определены, виновные найдены - дело за переменами, которые и были осуществлены. И называлось это политика «Нового курса» Ф. Рузвельта. Суть дела здесь такова. Экономический результат достигается посредством синтеза интересов хозяйствующих субъектов и населения страны в течение длительного времени, при этом следует иметь в виду, что экономическая деятельность не может возникнуть под патронажем «свободного рынка». Более того, следует оградить от этого самого «свободного» рынка население и общественное развитие. Именно это имел в виду Ф. Рузвельт, акцентируя внимание на необходимости ввода элементов планирования в американскую экономику. Это позволило ему победить депрессию в экономике и направить ее в русло динамичного развития.

На наш взгляд, заслуживает внимания высказывания профессора Сабура Окито, одного из творцов «японского экономического чуда», который считает, что «...утверждение о превосходстве рыночно ориентированной экономики над централизованной - это заблуждение. Проблема состоит в том, чтобы соединить, согласовать, объединить в едином механизме начала этих двух систем». [8, с. 1].

Отсутствие такого подхода чревато переходом бизнеса к краткосрочным проектам, что автоматически создает препятствия для серьезных инноваций, направленных на фундаментальные 
изменения не только в структуре национальной экономики, но и в структуре общества: размывание квалифицированных кадров, падение зарплат ученых, преподавателей, инженеров, старение кадров и их деградация, проблемы в школе и образовании в целом.

В самом общем виде миграция (внешняя и внутренняя) научных кадров происходит следующим образом: самые умные уезжают, средние уходят в бизнес, а оставшиеся идут в преподаватели. Такая система приводит к деградации научного сообщества. Начинается борьба за «мозги». В России Научно-исследовательские и опытно-конструкторские работы (разработки) не получают достаточно инвестиций из различных фондов, т.е. не работают на будущие поколения, тогда как в США 55\% НИОКР - это деньги пенсионных и страховых фондов. «Россия в 2012 г. имела только 3,5\% пенсионных накопления от ВВП, говорила О. Дмитриева (депутат ГД) в интервью на передаче «Деньги на старость» радиостанции «Вести ФМ» [9]. Доходность ВЭБ 6,6\%: управляющих компаний - 7\% НПФ 7,9\%; инфляция 10,1\%, где выгода гражданам страны от вкладывания их пенсионных накоплений? «Русский бизнес не вкладывается в НИОКР. В 2010-2012 гг. 80\% размещений акций компаний РФ прошло за рубежом. В Бразилии этот показатель составляет 7\%, в Китае - 8\%, в Индии - 14\%, в ЮАР - 29\%. «Для крупных стран такая ситуация уникальна. В данном аспекте Россию нельзя сравнить ни с одной страной БРИКС, только, пожалуй, с Украиной»,- резюмировала К. Юдаева [10, с. 2].

Подобное положение свидетельствует о том, что в современной России не сложилось понимание сути эффективности экономической составляющей, направленной на переход к экономике знаний.

Вместе с тем, несмотря на противоречивость государственного и рыночного начал в управлении общественным производством, роль первого для российской экономики переходного периода должна стать доминирующим. Это предполагает, что движущими силами экономики, наряду с материальными факторами, являются, являются моральные, этические и правовые.

В свете вышеизложенного необходимо выделить ряд проблем, сдерживающих процесс модернизации российской экономики и пути их решения. К ним относятся следующие: во-первых, либерализм на Западе явился следствием развития капиталистических отношений, а не причиной, как это произошло в России начала 19 века. Отсюда политическая составляющая продолжает превалировать над другими сторонами общественных перемен, что предполагает устранение последствий огосударствления на основе здоровой конкуренции и развития среднего предпринимательства, а также использования зарубежного опыта (Китая, Японии и США). Во-вторых, новые реалии, вызванные радикальными событиями, произошедшими в конце XX в. в России, требуют инновационного изменения общественной системы, а потому необходимо определить направления и суть действий, ориентированных на реализацию интересов всех слоев и страт российского общества. В-третьих, требуется развеять миф о превосходстве рыночно ориентированной экономики над централизованной, ибо суть дела здесь заключается в том, чтобы определить пути синтеза рыночных отношений и стратегического. В-четвертых, необходимо признать важнейшую роль местного самоуправления в социально-экономическом плане, и в плане развития гражданского общества и ориентировать его на удовлетворение интересов населения. В-пятых, оптимальное распределение трудовых ресурсов и материальных ресурсов, на федеральном, региональном и местном уровнях, что позволит достичь наибольших результатов в структурной модернизации российской экономики. В-шестых, кроме того, важную роль в этой модернизации должна сыграть эффективное использование потенциала внутренней миграции населения под определенные задачи, с определенной степенью образованности и организованности, на основе научных достижений, что должно являться уже первым признаком замаячившего супер-индустриального общества (опыт Китая).

Резюмируя вышеизложенное следует подчеркнуть, что решение указанных проблем выступает в качестве необходимой предпосылки структурной модернизации российской экономики обеспечение нового качества экономического роста и соответствующих этим процессам изменений социальной структуры общества в контексте его перехода к постиндустриального развитию. 


\section{Библиографический список}

1. Сычев Н.В. Проблемы модернизации российской экономики в контексте современных реалий //Экономические стратегии. 2018. № 2.

2. Никифоров Л.В. Смешанное общество: Российский вариант. Москва. 1999.

3. Социальное расслоение в Китае: сборник / Под ред. А. Наумова. Москва. 2016. С. 287.

4. http://www.grandars.ru/college/sociologiya/stratifikaciya-v-rossii.html

5. https://www.gazeta.ru/business/2014/10/30/6282685.shtmlhttp://svpressa.ru/society/article/146542/

6. http://svpressa.ru/society/article/146542/

7. Уткин А.И. Дипломатия Франклина Рузвельта. Свердловск. 1990.

8. http://politrussia.com/politkasha/gosudarstvennoe-regulirovanie-ekonomiki-869/

9. Дмитриева О. (депутат ГД) в интервью на передаче «Деньги на старость» радиостанции «Вести ФМ».

10. Доклад главы Экспертного управления президента России Ксении Юдаевой Денисова Москва. В офшоры бизнес выталкивают дефицит ликвидности и некомпетентные суды. 15 февраля 2013. http://opec. $\mathrm{ru} / 1459794 . h t m l$. 